\title{
Presença da lógica no domínio da organização do conhecimento:aspectos interdisciplinares no currículo do ensino superior
}

\section{Leilah Santiago Bufrem}

\begin{abstract}
Doutora em Ciências da Comunicação pela Universidade de São Paulo Pós-Doutora pela Universidad Autonoma de Madrid.Professora Titular do Departamento de Ciência e Gestão da Informação da Universidade Federal do Paraná, Curitiba, Paraná, Brasil.
\end{abstract}

Sônia Maria Breda

\begin{abstract}
Doutora em Educação pela Universidade Federal do Paraná. Professora do Departamento de Ciência e Gestão da Informação da Universidade Federal do Paraná, Curitiba, Paraná, Brasil.
\end{abstract}

Reflexão acerca da presença curricular da lógica no domínio da organização do conhecimento, particularmente no campo da Ciência da Informação (CI). Identifica, em programas de 72 escolas de CI no Brasil, o espaço curricular destinado à disciplina. Observa que os programas voltam-se à análise das formas de raciocínio e à representação do conhecimento. Analisa conteúdos disciplinares associados aos aspectos da lógica no currículo de CI e salienta a relevância da disciplina para os grandes domínios, nos quais se apoiam os processos de informação e enfatiza a necessidade de uma concepção transdisciplinar para a construção do currículo.

Palavras-chave: Lógica; Currículo; Ensino Superior; Ciência da Informação; Organização do Conhecimento.

\section{The presence of logic in the domain of knowledge organization: interdisciplinary aspects of college curricula}

A study is presented on the curricular presence of logic in the domain of knowledge organization, particularly in the 
field of Information Science (IS). The article attempts to identify the curricular space destined to this subject in the programs of 72 IS schools in Brazil. It was observed that the programs are turned to the analysis of the forms of reasoning and representation of knowledge. The article analyses the disciplinary contents linked to aspects of logic in the curriculum of IS and highlights the relevance of the subject to the great domains in which the processes of information are based, and emphasizes the need for an interdisciplinary conception.

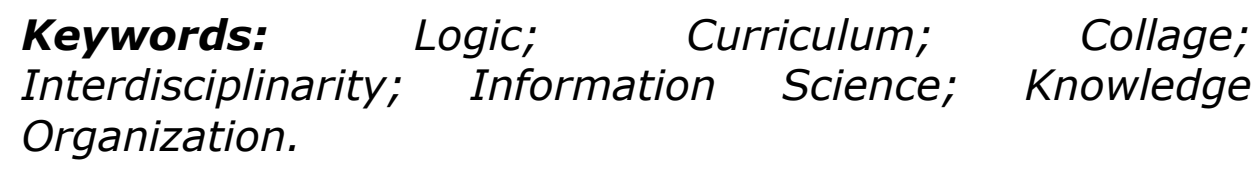

Recebido em 17.03.2010 Aceito em 10.01.2011

A técnica do pensamento não criará certamente grandes filósofos, mas fornecerá critérios de julgamento e de controle, bem como corrigirá as distorções do modo de pensar do senso

(GRAMSCI, 2006, p. 182).

\section{Introdução}

O legado gramsciano enaltece a noção de que o homem é filósofo, a seu modo, estabelecidos os limites e as distinções dessa "filosofia espontânea". Trata-se de conduzir os simples a uma concepção superior de vida, elevá-los de sua filosofia primitiva do senso comum, viabilizar um progresso intelectual de massa e não exclusivo de pequenos grupos intelectuais (GRAMSCI, 1995).

Pés na modernidade e olhar voltado à formação, relacionada à informação e conhecimento, impõe-se, sobremaneira, à lógica, técnica argamassa do pensamento. Ela tem sido desenvolvida como disciplina relacionada com saberes, especialmente a linguagem e a matemática, mas sua figura adquire contornos especiais ao adentrar o domínio profissional da organização do conhecimento (OC) e, mais particularmente, o campo da Ciência da Informação (CI).

Movida pelo desejo de desvendar aspectos dessa presença, objeto de uma pesquisa mais ampla realizada por Bufrem, Breda e Sorribas (2005; 2007), a presente reflexão parte dos questionamentos: Quais os principais conceitos da lógica encontrados nos currículos dos profissionais da informação do Brasil? Quais as evidências da contribuição da disciplina lógica para o currículo do gestor da informação?

Constituem objetivos desta análise, identificar, em programas das escolas de CI no Brasil, o espaço dado à disciplina no currículo, evidenciar 
as relações entre essa disciplina e as práticas e competências relativas ao perfil do profissional de informação, previsto nos cursos de graduação da área no país, e destacar os principais aspectos da lógica para atender à formação relacionada com OC. Nessa direção, se encaminha o processo reflexivo interessado na posição da lógica para o perfil profissional dos cursos de CI do Brasil, assim como nos conteúdos disciplinares relacionados a aspectos da lógica no e para o currículo de Gestão da Informação da Universidade Federal do Paraná, campo empírico de observação.

O corpus, constituído dos curricula de 72 cursos de CI, disponibilizados nos sites, é analisado em dois momentos: o primeiro, uma leitura e síntese de todo o material disponibilizado; o segundo, uma reflexão acerca da posição da lógica nesse universo, em que se privilegia a visão interdisciplinar.

\section{Presença curricular da lógica nos cursos de Ciência da Informação no Brasil}

Os $72 \operatorname{cursos}^{1}$ de graduação na área de CI no Brasil, referentes às 50 instituições de ensino superior, incluem 31 cursos de Biblioteconomia; 17 cursos de Arquivologia; 9 cursos de Museologia; 4 cursos de Ciência da Informação; 3 cursos de Biblioteconomia e Documentação; 2 cursos de Gestão da Informação; 2 cursos de Biblioteconomia e Ciência da Informação; 1 curso de Ciência da Informação e da Documentação; 1 curso de Biblioteconomia e Gestão da Informação; e 1 curso de Biblioteconomia e Gestão de Unidades de Informação. Como curso com habilitação, registra-se 1 curso de Biblioteconomia com habilitação em Gestão da Informação (GRÁF. 1). A estrutura curricular está disponibilizada nos sites de 52 cursos $(72,2 \%)$ e, destes, 26 disponibilizam também a ementa.

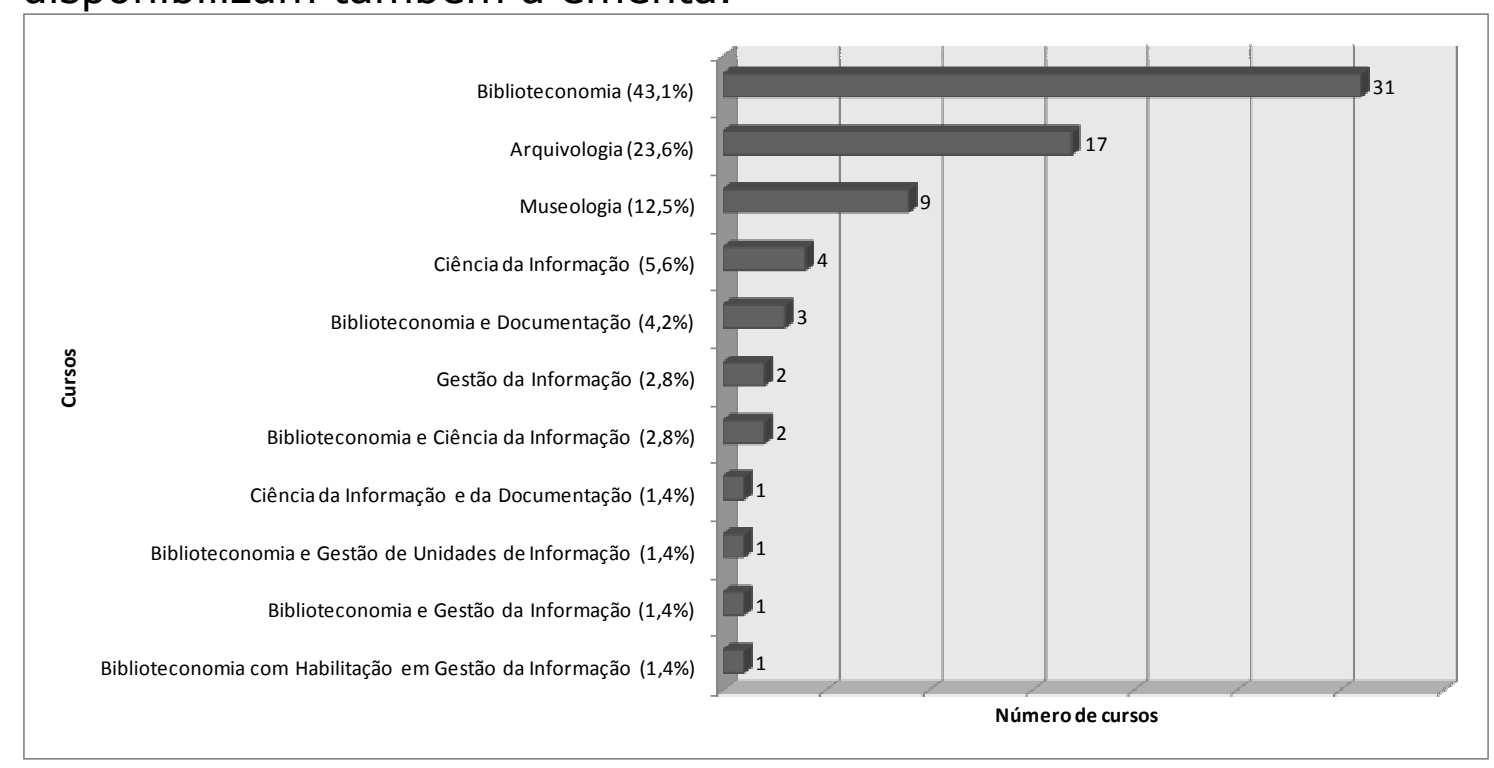

\footnotetext{
${ }^{1}$ Cursos superiores de instituições de educação superior credenciadas no Cadastro da Educação Superior do Ministério da Educação (BRASIL, 2009).
} 


\section{GRÁFICO 1 - Cursos da área de CI no Brasil}

Fonte: Dados da pesquisa.

Predominam as universidades federais, entre as cinquenta instituições de ensino superior que oferecem os 72 cursos na área de CI, representados por 20 instituições, atingindo 40\% desse universo (GRÁF. 2).

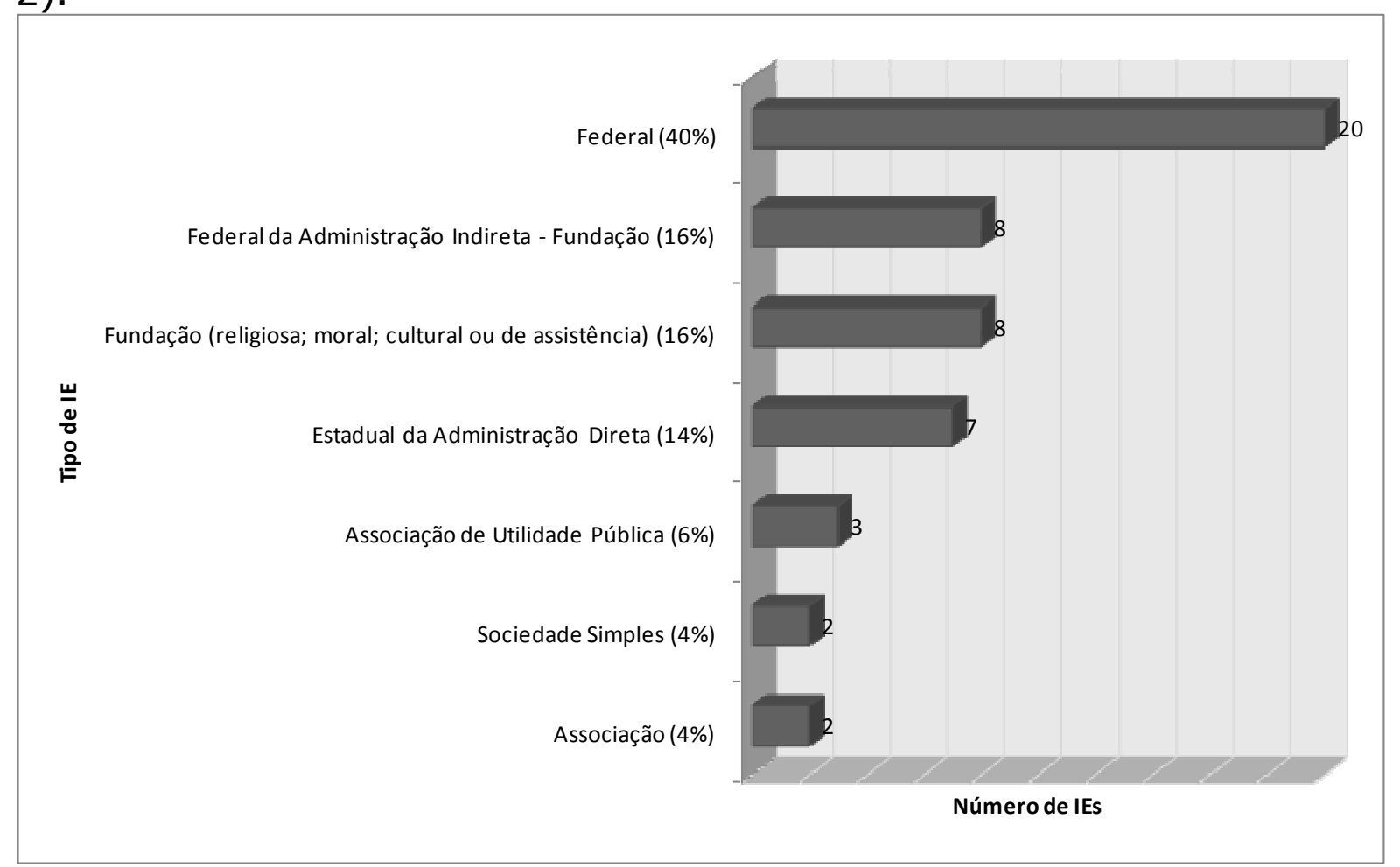

\section{GRÁFICO 2 - Tipo de IES}

Fonte: Dados da pesquisa.

Categorizados pela região geográfica em que se situam no Brasil, observa-se, no GRAF. 3, que a maioria, $42 \%$ das instituições que oferecem os cursos, encontra-se na região sudeste, seguida pela região nordeste, com $24 \%$ dos cursos e pela região sul, com $18 \%$. Com menor expressão numérica, seguem-se as regiões centro-oeste, com $10 \%$ e a região norte, com $6 \%$ do total de cursos. A distribuição regional dos cursos da área mostra-se assimétrica, uma vez que quase a metade deles concentra-se na região sudeste, destacando-se, assim, as regiões centrooeste e norte como as mais carentes. O panorama condiz com a configuração do ensino superior brasileiro, que torna visível uma concentração decorrente dos fatores socioeconômicos, propulsores do desenvolvimento de cada região. No tocante à formação em Informação, essa concentração representa causa e efeito do aceite de um paradigma ainda ditado pela subalternidade, por uma espécie de "laissez-faire" cultural, o que põe em destaque pensar criticamente o papel exercido pela lógica nesses processos formativos. 


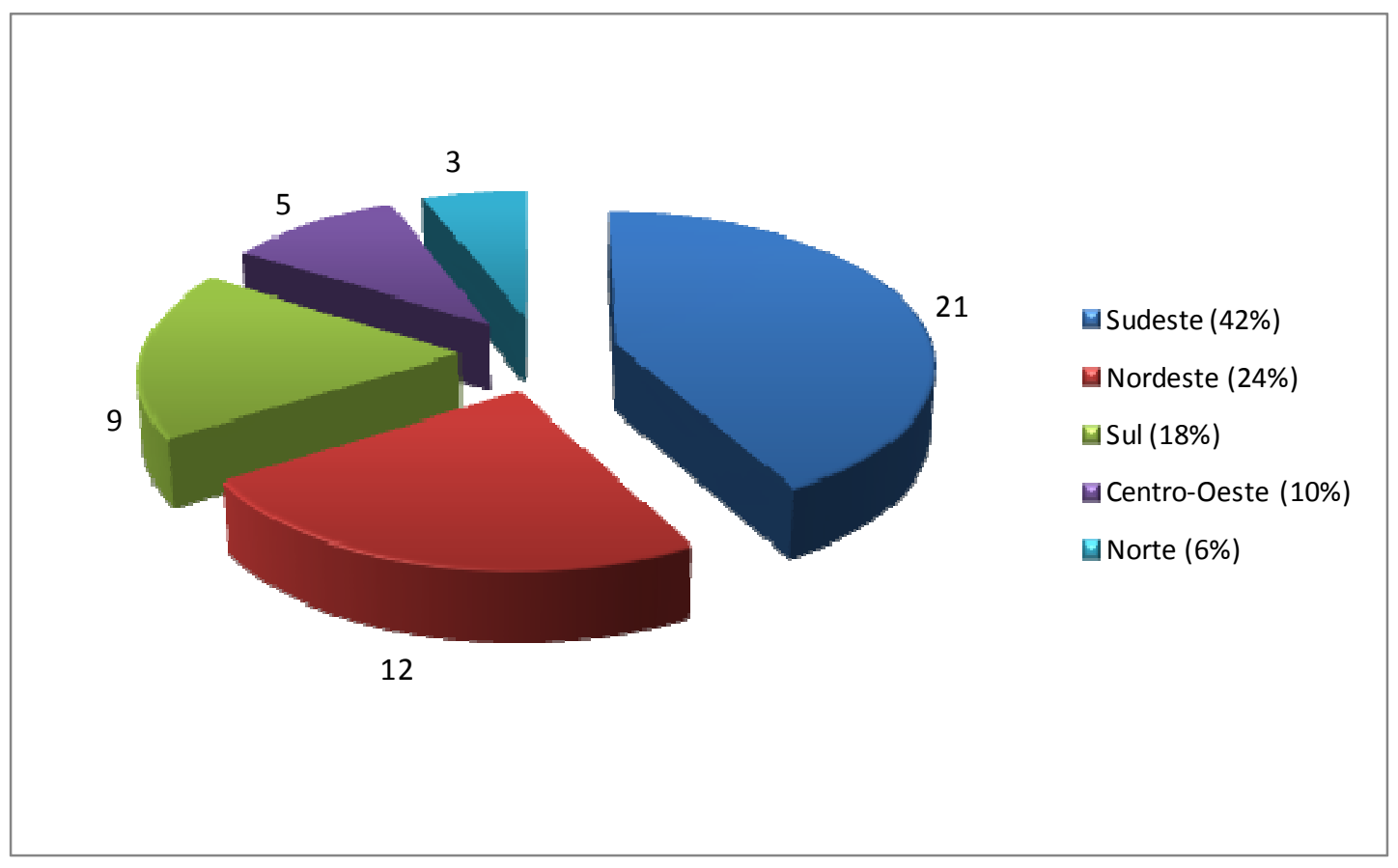

GRÁFICO 3 - Número de IEs por região geográfica do Brasil

Fonte: Dados da pesquisa.

A posição da lógica como disciplina para a formação em CI é observada em 33 cursos (63,5\%), dos 52 que disponibilizam a estrutura curricular, incluindo cursos de Biblioteconomia, Ciência da Informação, Gestão da Informação e Arquivologia, mas não faz parte da composição curricular dos cursos de Museologia.

A análise considera resultados de estudos anteriores, pautados na literatura em $\mathrm{CI}$, pelos quais se observa o ambiente da $\mathrm{OC}$ imbricado com espaços alternativos, descobertas e avanços tecnológicos, cujas fronteiras foram ampliadas na direção de temáticas como gestão do conhecimento e inteligência competitiva. Diante dos diferentes olhares e da extensão do domínio da OC, identifica-se um quadrante em que se impõem para a atuação profissional tarefas em ritmo de expansão e de especificações mais precisas, relacionadas a um paradigma, em que estariam incluídos os termos inteligência artificial, sistema esperto, monitoramento tecnológico e outros que a literatura apresenta para significar uma direção estrutural pragmática, no sentido de facilitar a representação e utilização do conhecimento adquirido e organizado.

Além da relação de reciprocidade ou mutualidade entre conceitos, práticas ou aspectos de um fenômeno ou de uma área do saber, a leitura das contribuições conduz a considerações conclusivas, com destaque para a tendência em direção a uma base teórica e epistemológica que facilite a linguagem comum, para 0 sucesso na compreensão de conceitos fundamentais da área de CI.

Do ponto de vista pedagógico, deve-se estar atento à dimensão relacional da lógica curricular, cuja apropriação como uma espécie de disciplina ou saber "instrumental" requer cuidados ao tratar de uma 
essência que potencialmente se nutre e é nutrida por outras disciplinas. Isso equivale a levar em consideração pedagógica aspectos que extrapolam a medida de conteúdo dos saberes envolvidos em um dado currículo, e a encarar a metodologia de ensino de cada (outra) disciplina como eixos articulados de aproximação e intersecção à lógica presente no curso, promovendo uma concepção e uma prática efetivamente interdisciplinares ${ }^{2}$. No panorama da formação em CI analisado, a fragmentação disciplinar ainda sobressai, sinalizando uma aresta formativa merecedora de atenção

A análise dos cursos permite afirmar: a) os programas estudados voltam-se, predominantemente, à análise das formas de raciocínio e à representação do conhecimento; b) apresentam, de modo mais ou menos abrangente, tópicos sobre natureza e estruturas relativas aos conceitos, assim como as relações entre eles; c) indicam o domínio de conceitos introdutórios a modelos representacionais associados a sistemas de bancos e bases de dados, à teoria da classificação facetada e suas possibilidades; e d) voltam-se ao método de raciocínio, ao objeto de representação, às relações entre os objetos e às formas de representação.

\section{Conteúdos disciplinares de CI como elementos para um programa "com lógica"}

No intuito de destacar os principais aspectos da lógica para atender à formação relacionada à OC, foram analisados os conteúdos disciplinares compatíveis com a presença da matéria no currículo dos cursos analisados, do que resultam subsídios para a discussão de um programa com enfoque transdisciplinar, em que a lógica se faz presente.

Os conteúdos disciplinares, abaixo elencados, resultam dessa análise, que toma por referência o Curso de Gestão da Informação da UFPR:

Algoritmos e estruturas de dados: categorias; conceitos de extensão e intensão (compreensão); árvores conceituais; cálculo proposicional; estruturas binárias e não binárias; cortes de domínios; álgebra de Boole; algoritmos de modelização; desenvolvimento de algoritmos.

Análise da informação e do conhecimento: conceitos, termos e definições; conceitos de extensão e intensão; analítica formal do juízo; lógica sentencial; analítica do raciocínio; argumentos dedutivos: categóricos, hipotéticos, incompletos e compostos; enumeração, analogia e generalização; silogismos e suas regras; cálculo de predicado; simbolização; interpretação.

\footnotetext{
${ }^{2}$ Vale salientar que a noção de transdisciplinaridade mais próxima dessa concepção está presente na Carta da transdisciplinaridade, produzida pela UNESCO, no I Congresso Mundial de Transdisciplinaridade 1994, realizado em Arrábida, Portugal, no artigo 3: "[...] a transdisciplinaridade não procura o domínio sobre várias outras disciplinas, mas a abertura de todas elas àquilo que as atravessa e as ultrapassa [...]" e 7: "A transdisciplinaridade não constitui nem uma nova religião, nem uma nova filosofia, nem uma nova metafísica, nem uma ciência das ciências" (CONGRESSO MUNDIAL DE TRANSDISCIPLINARIDADE, 1994).
} 
a) Bancos de dados: lógica matemática e proposicional; álgebra de Boole; teoria dos conjuntos; conjuntos enumeráveis; conjuntos nãoenumeráveis; operações com conjuntos.

b) Condensação da informação: conceitos, termos e definições; conceitos de extensão e intensão; analítica formal do juízo; lógica sentencial; analítica do raciocínio; silogismos e suas regras; interpretação; enumeração, analogia e generalização.

c) Engenharia de software: modelos conceituais; modelos de representação; desenvolvimento de algoritmos; programação de estruturas de controle; subprogramas; simbolização; interpretação; enumeração; analogia e generalização; teoria dos conjuntos; cálculo proposicional.

d) Indexação da informação: conceitos, termos e definições; conceitos de extensão e intensão; analítica formal do juízo; lógica sentencial; analítica do raciocínio; silogismos e suas regras; interpretação; enumeração, analogia e generalização.

e) Infometria: interpretação; enumeração, analogia e generalização; cálculo proposicional.

f) Metadados e linguagem de marcação: simbolização; interpretação; cálculo proposicional; modelos de representação; enumeração, analogia e generalização; teoria dos conjuntos.

g) Metodologia da pesquisa: conceitos, termos e definições; conceitos de extensão e intensão; analítica formal do juízo; analítica do raciocínio; argumentos dedutivos: categóricos, hipotéticos, incompletos e compostos; validade dos argumentos categóricos; argumento indutivo e probabilidade indutiva; silogismos e suas regras; natureza lógica do discurso; interpretação; enumeração, analogia e generalização; falácias formais e informais.

h) Mineração de dados: árvores conceituais; álgebra de Boole; estruturas binárias e não binárias; conceitos de extensão e intensão; cortes de domínios; permutação e combinação.

j) Monitoramento da informação: árvores conceituais; álgebra de Boole; estruturas binárias e não binárias; conceitos de extensão e intensão; cortes de domínios; permutação e combinação.

k) Ontologia e taxonomia do conhecimento: conceitos, termos e definições; conceitos de extensão e intensão; analítica formal do juízo; lógica sentencial; analítica do raciocínio; simbolização; interpretação; enumeração, analogia e generalização.

I) Organização, sistemas e métodos: analítica formal do juízo; analítica do raciocínio; argumentos dedutivos: categóricos, hipotéticos, incompletos e compostos; validade dos argumentos categóricos; argumento indutivo e probabilidade indutiva; enumeração, analogia e generalização.

m) Produção de texto: natureza lógica do discurso; lógica sentencial; termos e conceitos; analítica formal do juízo analítica do raciocínio; argumentos dedutivos: categóricos, hipotéticos, incompletos e compostos; validade dos argumentos categóricos; argumento indutivo e 
probabilidade indutiva; reconhecimento de estruturas lógicas no texto; estruturas lógicas e organização da informação.

n)Projeto de pesquisa em informação: conceitos, termos e definições; conceitos de extensão e intensão; analítica formal do juízo; analítica do raciocínio; argumentos dedutivos: categóricos, hipotéticos, incompletos e compostos; argumento indutivo e probabilidade indutiva; silogismos e suas regras; natureza lógica do discurso; interpretação; enumeração, analogia e generalização.

Esses elementos devem contribuir para a discussão sobre o espaço curricular da lógica na formação em CI, em enfoque interdisciplinar.

\section{Considerações finais}

O estudo da lógica, como insumo dos saberes, traz para o centro de atenção a constituição do pensar e produzir científicos, processo construtivo permeado de um elenco de particularidades históricas mais pressupostas do que efetivamente percebidas e iluminadas pelo debate. Se, por um lado, com esta análise sobre a presença da lógica curricular na formação em CI no Brasil, contribuiu-se para ratificar sua relevância teórico-prática no domínio da OC, por outro, demonstrou-se a necessidade de uma vigilância crítica com vistas a uma integração de conteúdos disciplinares.

Há evidências de que tanto a organização da informação, quanto a organização do conhecimento, adotam recursos que não prescindem de formas lógicas e bases teóricas da classificação. A lógica está presente tanto nas estratégias utilizadas pela informática, nos menus/diretórios, na construção dos índices e de ferramentas de busca, quanto na varredura de textos e nas ontologias construídas para a chamada "inteligência artificial". Esta, concebida como alternativa pragmática para um melhor tratamento dos problemas relacionados à manipulação de informação em meio eletrônico, apresenta-se com dois tipos de solução não mutuamente exclusivos, como argumenta Freitas (2004). O primeiro, segundo o autor, para dotar os sistemas de inteligência e autonomia, quando do aprimoramento da busca e seleção da informação na rede. O segundo, procurando aperfeiçoar a própria Internet, dotando-a de inteligência, para que suas páginas tenham uma semântica clara e definida, e que agentes possam raciocinar sobre esta semântica, ideia originária da Web Semântica. Com efeito, as ontologias - especificação dos conceitos de um determinado domínio e suas relações, restrições e axiomas, definidos de forma declarativa - representam um papel fundamental em ambas as soluções.

Cabe acrescentar que os princípios lógicos são necessários e determinantes para os processos de planejamento e tomada de decisões. Salienta-se a contribuição da lógica, com todos os seus desdobramentos, para os cinco grandes domínios nos quais se apoiam os processos de 
gestão da informação: a Administração, a Ciência da Informação, a Comunicação, a Informática e a Linguística.

Das constatações, decorre a necessidade de uma concepção transdisciplinar das áreas voltadas à $O C$, sem que se desprezem, entretanto, as identidades disciplinares necessárias ao aprofundamento em questões relativas a um domínio específico de conhecimento. Cabe, ainda, preservar, como objeto especial do que se denomina OC, as dimensões relativas ao produto concreto do processo de conhecer.

\section{Referências}

BUFREM, L. S. Aplicações da lógica ao campo da Gestão da Informação. Curitiba, 2005. [Palestras].

BUFREM, L. S.; BREDA, S. M.; SORRIBAS, T. V. The presence of logic in the domain of knowledge organization: interdisciplinary aspects of college curricula. In: CONGRESSO ISKO-ESPAÑA, 8., 2007, León. La Interdisciplinariedad y la transdisciplinariedad en la organización del conocimiento científico. León: Universidad de León, 2007. p. 179-185.

CONGRESSO MUNDIAL DE TRANSDISCIPLINARIDADE, 1., 2-6 nov. 1994, Convento Arrábida, Lisboa, Portugal. Carta da transdisciplinaridade. Lisboa, Portugal, 1994.

FREITAS, F. L. G. Ontologias e a Web Semântica. Programa de PósGraduação em Informática, Universidade Católica de Santos, Santos, SP, 2004. Disponível

em: <http://www.inf.ufsc.br/ gauthier/EGC6006/material/Aula\%203/Ontologi a Web semantica\%20Freitas.pdf>. Acesso em: 03 mar. 2010.

GRAMSCI, A. Cadernos do cárcere. Rio de Janeiro: Civilização Brasileira, 2006. v. 1.

\section{Bibliografia consultada}

ARISTÓTELES. Categorias. Lisboa: Instituto Piaget, 2000.

BOGGINO, N. Como elaborar mapas conceptuales: aprendizaje significativo y globalizado. Rosario: Homo Sapiens, 2002.

BRASIL. Ministério da Educação. Cadastro da Educação Superior. Brasília: MEC, 2009. Disponível em: <http://emec.mec.gov.br/>. Acesso em: 15 mar. 2010.

CAMPOS, A. T. O processo classificatório como fundamento das linguagens de indexação. Revista de Biblioteconomia de Brasília, Brasília, v. 6, n. 1, p. $1-8,1978$.

CAMPOS, M. L. A. Modelização de domínios de conhecimento: uma investigação de princípios fundamentais. Ci. Inf., Brasília, v. 33, n.1, p. 22-32, jan./abr. 2004. 
CAMPOS, M. L. A.; GOMES, H. E. Organização de domínios de conhecimento e os princípios ranganathianos. Perspect. Ciênc. Inf., Belo Horizonte, v. 8, n. 2, p. 150-163, jul./dez. 2003.

CHAUI, M. Introdução à história da filosofia: dos pré-socráticos a Aristóteles. São Paulo: Companhia das Letras, 2002. v. 1.

DAHLBERG, I. Fundamentos teórico-conceituais. Revista de Biblioteconomia de Brasília, v. 6, n. 1, p. 9-21, 1978.

FARIA, W. Mapas conceituais: aplicações ao ensino, currículo e avaliação. São Paulo: EPU, 1995.

GRAMSCI, A. Concepção dialética da história. Rio de Janeiro: Civilização Brasileira, 1987.

KRIEGER, M. G.; FINATTO, M. J. B. Introdução à terminologia: teoria e prática. São Paulo: Contexto, 2004.

LEÃO, L. O labirinto da hipermídia: arquitetura e navegação no ciberespaço. São Paulo: Fapesp, 2001.

LEAUBY, B. A.; BRAZINA, P. Concept mapping: potential uses in accouting education. Journal of accouting education, London, v. 16, n.1, p. 123-138, 1998.

LEVY, P. As árvores de conhecimentos, um instrumento para a inteligência coletiva na educação e na formação. In: LEVY, P. Cibercultura. Rio de Janeiro: Ed. 34, 1997. cap. 12.

LEVY, P.; AUTHIER, M. As árvores do conhecimento. São Paulo: Escuta, 1995.

LIMA, G. A. B. Mapa conceitual como ferramenta para organização do conhecimento em sistema de hipertextos e seus aspectos cognitivos. Perspect. Ciênc. Inf., Belo Horizonte, v. 9, n. 2, p. 134-145, jul./dez. 2004.

OATES, T.; PRASAD, M.; LESSER, V. Cooperative information gathering: a distributed problem solving approach. IEE Proceedings on Software Engineering, Massachusetts, USA, v. 144, n. 1, p. 72-88, February 1997. Disponível em: <ftp://mas.cs.umass.edu/pub/oates IEE 97.pdf>. Acesso em: 03 mar. 2010.

PENZIAS, A. Idéias e informação: operando num mundo de alta tecnologia. Lisboa: Gradiva, 1991.

POPPER, K. R.; ECCLES, J. C. O cérebro e o pensamento. Brasília: Ed. UnB, 1992.

. O eu e seu cérebro. Brasília: Ed. UnB, 1995.

TENÓRIO, R. M.. Cérebros e computadores: a complementaridade analógico-digital na informática e na educação. São Paulo: Escrituras, 1998. 